\title{
Lattice Dynamical Study and Elastic Property of Europium Telluride (EuTe) Crystal
}

\author{
SHYAMENDRA PRATAP SINGH ${ }^{1 *}$ and U. C. SRIVASTAVA ${ }^{2 *}$ \\ 'Department of Physics, Swami Vivekanand Govt. P. G. College, Lohaghat, Champawat, \\ Uttara Khand, India. \\ 2Department of Physics, Amity Institute of Applied Sciences, Amity University, Noida-UP, India. \\ *Corresponding author E-mail: ucsrivastava@amity.edu, spsinghsps.21@gmail.com
}

http://dx.doi.org/10.13005/ojc/370511

(Received: July 31, 2021; Accepted: October 11, 2021)

\begin{abstract}
In the present work authors are reporting complete lattice dynamical properties of Europium telluride (EuTe). The present model works on three body rigid ion model \& three body rigid shell model (TRIM \& TRSM). The short-range overlap repulsion is operative up to the second neighboring ions. An excellent agreement has been obtained between theory and experiment for their all-phonon properties of (EuTe) like phonon dispersion curves, Debye temperature variations, two-phonon IR/Raman spectra, third-fourth order lattice constant, pressure derivative and anharmonic elastic properties.
\end{abstract}

Keywords: Phonon dispersion curves, Debye temperature variations, Two-phonon IR/Raman spectra, Third-fourth order lattice constant, Pressure derivative, Anharmonic elastic properties.

\section{INTRODUCTION}

The electronic structure of Europium telluride (EuTe), which is a family of Europium Chalcogenides crystallize in F.C.C. $\mathrm{NaCl}$ structure and are also called rare earth europium chalcogenides. Europium Telluride (EuTe) is a crystal grown product generally immediately available in most volumes. Unlike other rare earth compounds europium chalcogenides generally, show non-mixed valance character. Complete experimental data on phonon dispersion is available for EuTe, which has been reported. by Silberstein et al., ${ }^{1}$. Zeyher and Kress $^{2}$ discuss the complete phonOn dispersion curves (PDC), combined density of states (CDS) ${ }^{3}$ and Debye temperature variations curve given by 4 . The parameters like elastic \& dielectric constants ${ }^{5,6}$, the physical-natural properties of the (EuTe) have been attracted and their explication through different conceptual models ${ }^{7-12}$, which has also satisfyingly narrated their engrossing properties. It has been establishing the interactions of three body which demonstrate the optical branches and Cauchy discrepancy concurrently to almost all the ionicsemiconducting crystals ${ }^{13}$. The remarkable success achieved from (RIM) $)^{14}$ and $(\mathrm{RSM})^{15}$ represent the lattice properties of alkali halides and worthwhile to explore the adequacies of these model for EuTe. The third-order elastic constants (TOEC), which is related to the energy products of three strain

This is an Open Access article licensed under a Creative Commons license: Attribution 4.0 International (CC- BY). Published by Oriental Scientific Publishing Company @ 2018

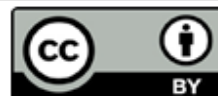


components, and the lowest order constants to enter the description of non-linear effects like the equation of state and the interaction of phonons. These TOEC is determined from velocity measurements on small amplitude sound waves in statically stressed media. The aim of present report is to test the applicability and utility of second-neighbor three-body rigid shell model (TRSM) and second neighbor three-body rigid ion model (TRIM) with the satisfactory description of phonon dispersion relations and other phonon properties of the EuTe.

\section{Theory}

The existing model accordingly consists of the comprehensive shield coulomb, TBI and the short-range overrun repulsion effective up to the next-neighbor for EuTe. The relevant expression for the crystal potential per unit cell can be extrapolate TBFSM, is given as

$\Phi=\Phi^{\mathrm{C}}+\Phi^{\mathrm{R}}+\Phi^{\mathrm{TBI}}$

where $\Phi^{\mathrm{C}}$ is comprehensive Coulomb reciprocity potential. where $\Phi^{\mathrm{R}}$ is a short-range repulsion \& $\Phi^{\mathrm{TB} I}$ long-range $\mathrm{TBI}$ interaction potential by ${ }^{16}$. The secular determinant equation is given by:

$$
\left|\underline{D}(\vec{q})-\omega^{2} \underline{M} \underline{I}\right|=0
$$
is given as:

The dipole's (VWI) efficient next- neighbor

$\Phi_{d d}^{L W I}(r)=-S_{V}\left|\frac{C_{++}+C_{--}}{6 r^{6}}\right|=\Phi^{V}(r)$

By use of Eq. (2) the Eq. for elastic constants can give as:

$$
\begin{aligned}
& C_{11}=\frac{e^{2}}{4 r_{0}^{4}}\left[-5.112 Z_{m}{ }^{2}+A_{12}+\frac{1}{2}\left(A_{11}+A_{22}\right)+\frac{1}{2}\left(B_{11}+B_{22}\right)+9.3204 \xi^{\prime 2}\right] \\
& C_{12}=\frac{e^{2}}{4 r_{0}^{4}}\left[0.226 Z_{m}{ }^{2}-B_{12}+\frac{1}{4}\left(A_{11}+A_{22}\right)-\frac{5}{4}\left(B_{11}+B_{22}\right)+9.3204 \xi^{\prime 2}\right] \\
& C_{44}=\frac{e^{2}}{4 r_{0}^{4}}\left[2.556 Z_{m}{ }^{2}+B_{12}+\frac{1}{4}\left(A_{11}+A_{22}\right)+\frac{3}{4}\left(B_{11}+B_{22}\right)\right]
\end{aligned}
$$

\section{Vibrational Properties of EuTe}

The term fo is based on overlap integrals of charge $\left(\mathrm{e}^{-}\right)$wave functions and expressions for optical vibration frequencies $\left(\omega_{L}\right.$ and $\left.\omega_{T}\right)$ are given as:

$$
\left(\mu \omega_{L}^{2}\right)_{q=0}=R_{0}^{\prime}+\frac{\left(Z^{\prime} e\right)^{2}}{v f_{L}} \cdot \frac{8 \pi}{3}\left(z_{m}^{2}+6 \xi^{\prime 2}\right)
$$

$\left(\mu \omega_{T}^{2}\right)_{q=0}=R_{0}^{\prime}-\frac{\left(Z^{\prime} e\right)^{2}}{\mathrm{v} f_{T}} \cdot \frac{4 \pi}{3} Z_{m}{ }^{2}$

By using Debye's model distribution function for frequency is given by

$\Theta_{\mathrm{D}}=h v_{\mathrm{m}} / \mathrm{K}$

the density of states of phonon for each polarization is given by

$$
\mathrm{g}(\omega)=\mathrm{dN} / \mathrm{d} \omega={ }_{N} \int_{B Z} \sum_{j} \delta\left[\omega-\omega_{j}(q)\right] d q=\left(\mathrm{VK}^{2} / 2 \pi^{2}\right) \cdot \mathrm{dK} / \mathrm{d} \omega
$$

and $\mathrm{N}=(\mathrm{L} / 2 \pi)^{3}\left(4 \pi \mathrm{K}^{3} / 3\right)$ and phonon wave vector $\mathrm{q}$ such that $\int g(\omega) d \omega=1$

\section{Numerical computations}

The input data and calculated model parameters from SMTRSM and SNTRIM for EuTe are given in Table 2 .

\begin{tabular}{|c|c|c|c|c|}
\hline \multicolumn{2}{|c|}{ Input data for EuTe } & \multicolumn{3}{|c|}{ Model parameters for EuTe } \\
\hline Properties & $\begin{array}{l}\text { Values } \\
\text { for EuTe }\end{array}$ & Parameters & TRSM & TRIM \\
\hline$C_{11}$ & 9.36 & $r_{0} f_{0}^{\prime}$ & -0.0262 & -0.0262 \\
\hline $\mathrm{C}_{12}$ & 0.67 & $\mathrm{Z}_{\mathrm{m}}{ }^{2}$ & 0.5965 & 0.5722 \\
\hline $\mathrm{C}_{44}$ & 1.63 & A & 12.702 & 12.6113 \\
\hline$r_{0}$ & 0.24 & B & -0.6950 & -0.6667 \\
\hline$\alpha 1$ & 8.76 & $d_{1}$ & 0.4136 & ------- \\
\hline \multirow[t]{3}{*}{$\alpha_{2}$} & 3.292 & $d_{2}$ & 0.9680 & -------- \\
\hline & & $Y_{1}$ & -0.2382 & $---\cdot$ \\
\hline & & $\mathrm{Y}_{2}$ & -3.7420 & 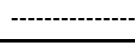 \\
\hline
\end{tabular}

Table 1: Cauchy-Discrepancy (in units $10^{12}$ dyne/cm²) for EuTe

\begin{tabular}{lc}
\hline \multicolumn{2}{c}{ Cauchy-Discrepancy } \\
Property & Values for EuTe \\
\hline $\mathrm{C}_{112}-\mathrm{C}_{166}$ & -0.3501831 \\
$\mathrm{C}_{123}-\mathrm{C}_{456}$ & 0.2610215 \\
$\mathrm{C}_{144}-\mathrm{C}_{456}$ & 0.0870346 \\
$\mathrm{C}_{123}-\mathrm{C}_{144}$ & 0.1739869 \\
$\mathrm{C}_{1112}-\mathrm{C}_{1166}$ & 2.3062965 \\
$\mathrm{C}_{1122}-\mathrm{C}_{1266}$ & 0.1261647 \\
$\mathrm{C}_{1122}-\mathrm{C}_{4444}$ & 0.637605 \\
$\mathrm{C}_{1123}-\mathrm{C}_{1144}$ & -0.0232144 \\
$\mathrm{C}_{1123}-\mathrm{C}_{1456}$ & -0.1482605 \\
$\mathrm{C}_{1123}-\mathrm{C}_{1244}$ & -0.4385078 \\
$\mathrm{C}_{1123}-\mathrm{C}_{4466}$ & -0.4158073 \\
\hline
\end{tabular}

Table 2: Input data, model parameters for EuTe in$C_{i j}$ (in $10^{12} \mathrm{dyn} / \mathrm{cm}^{2}$ ), ro(in $10^{-8} \mathrm{~cm}$ ) 
Table 3: Combined Density States curve for EuTe

\begin{tabular}{ccc}
\hline $\begin{array}{c}\text { Raman Active-(Present study) } \\
\text { Frequency In (THz) }\end{array}$ & Branch & Values $\left(\mathrm{cm}^{-1}\right)$ \\
\hline 42 & $\mathrm{LO}(\mathrm{X})$ - $\mathrm{LA}(\Delta)$ & 43 \\
74 & $\mathrm{LO}(\mathrm{X})-\mathrm{TA}(\mathrm{X})$ & 75 \\
116 & $\mathrm{LA}+\mathrm{TA}(\mathrm{X})$ & 118 \\
157 & $\mathrm{LA}(\mathrm{X})+\mathrm{TA}(\Delta)$ & 158 \\
172 & $2 \mathrm{LA}(\Delta)$ & 172 \\
189 & $\mathrm{TO}+\mathrm{LA}(\Delta)$ & 189 \\
206 & $2 \mathrm{TO}(\Delta)$ & 205 \\
234 & $2 \mathrm{LO}(\mathrm{X})$ & 233 \\
257 & $2 \mathrm{LO}(\Delta)$ & 255 \\
287 & $2 \mathrm{LO}(\Gamma)$ & 286 \\
\hline
\end{tabular}

Table 4: TOEC \& FOEC (in units $10^{12} \mathrm{dyne} / \mathrm{Cm}^{2}$ ), Pressure derivatives of SOEC and TOEC for EuTe

\begin{tabular}{lccc}
\hline $\begin{array}{c}\text { TOEC and FOEC } \\
\text { (in units } 10^{12} \mathrm{dyn} / \mathrm{Cm}^{2} \text { ) }\end{array}$ & \multicolumn{2}{c}{$\begin{array}{c}\text { Pressure derivatives of SOEC } \\
\text { and TOEC(dimensionless) }\end{array}$} \\
\hline Property & EuTe (Present) & Property & EuTe (Present) \\
\hline $\mathrm{C}_{111}$ & 2543.4513 & $\mathrm{dK}^{\prime} / \mathrm{dP}$ & 66.328857 \\
$\mathrm{C}_{112}$ & -1.9844249 & $\mathrm{dS}^{\prime} / \mathrm{dP}$ & 36.399633 \\
$\mathrm{C}_{123}$ & 1.2280826 & $\mathrm{dC}^{\prime}{ }_{44} / \mathrm{dP}$ & -2.7321557 \\
$\mathrm{C}_{144}$ & 1.0540957 & $\mathrm{dC}{ }_{111} / \mathrm{dP}$ & -4263.2546 \\
$\mathrm{C}_{166}$ & -1.6342418 & $\mathrm{dC}^{\prime}{ }_{112} / \mathrm{dP}$ & -3.3262317 \\
$\mathrm{C}_{456}$ & 0.9670611 & $\mathrm{dC}^{\prime}{ }_{166} / \mathrm{dP}$ & 2.7392656 \\
$\mathrm{C}_{1111}$ & 3483.4014 & $\mathrm{dC}^{\prime}{ }_{123} / \mathrm{dP}$ & 2.0584741 \\
$\mathrm{C}_{1112}$ & 8.0187951 & $\mathrm{dC}^{\prime}{ }_{144} / \mathrm{dP}$ & -1.7668426 \\
$\mathrm{C}_{1166}$ & 5.7124986 & $\mathrm{dC}^{\prime}{ }_{456} / \mathrm{dP}$ & 1.6209 \\
$\mathrm{C}_{1122}$ & 8.0187951 & & \\
$\mathrm{C}_{1266}$ & 7.3894107 & & \\
$\mathrm{C}_{4444}$ & 7.9006065 & & \\
$\mathrm{C}_{1123}$ & -1.9385487 & & \\
$\mathrm{C}_{1144}$ & -1.9617631 & & \\
$\mathrm{C}_{1244}$ & -2.3770565 & & \\
$\mathrm{C}_{1456}$ & -2.0868092 & & \\
$\mathrm{C}_{4466}$ & -2.35435 & & \\
\hline
\end{tabular}

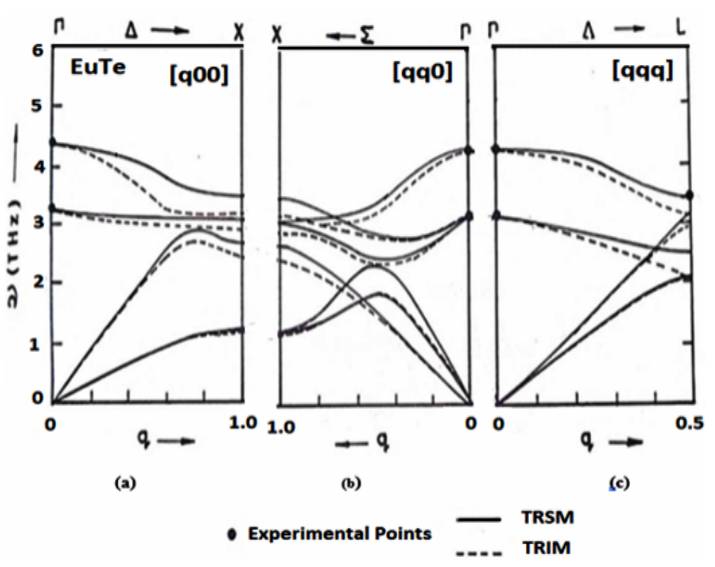

Fig. 1. Phonon Dispersion Curve for [EuTe]

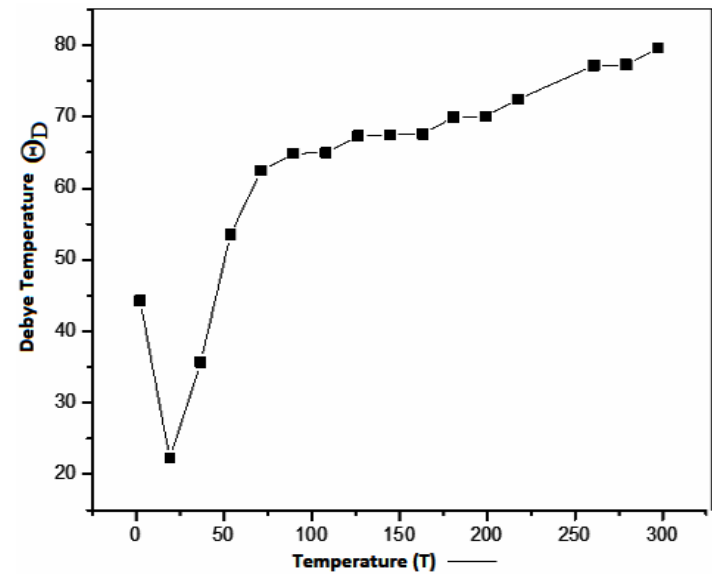

Fig. 2. Debye temperature curve for [EuTe]

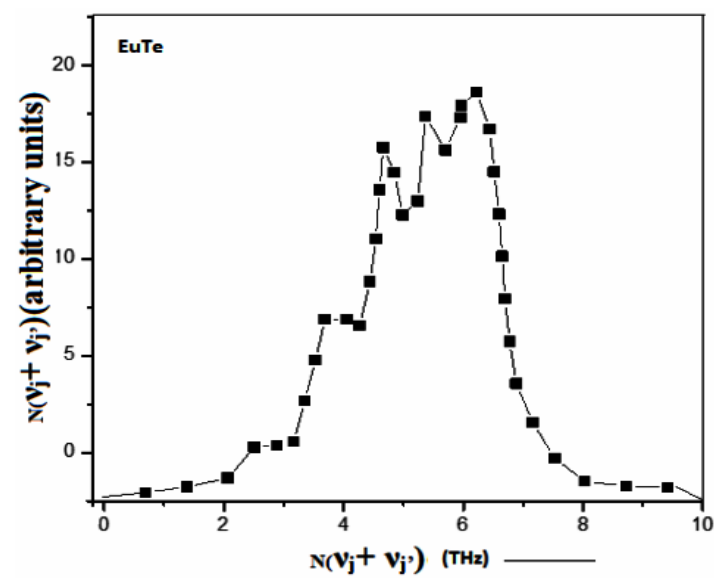

Fig. 3. Combined density of states curve for [EuTe]

RESULTS

The present approach is effectively described the crystal dynamics of (EuTe), eight parameter's with elastic constants $\left(\mathrm{C}_{11}, \mathrm{C}_{12} \& \mathrm{C}_{44}\right)$, six short range force constants parameters $r_{0} f_{0}$ ', ionic charge $z$, shell charge $Y$, polarizabilities $\left(a_{1}\right.$, $a_{2}$ ) \& polarizability (mechanical) 'd' developed by ${ }^{16}$ for (EuTe) are reported in Table 1 by using Eq.1 \& 2. The knowledge of lattice vibration frequency (CDSc) reports in Table 2 by computing $N$ $\left(v_{j}+v_{j}^{\prime}\right)$ of the combined frequencies $\left(v_{j}+v_{i}^{\prime}\right)$. The combined density data is reported in Table 3 . The sensitivity of two-phonon Raman spectra is towards high-frequency side of the phonon spectra \& specific heats towards its lower side is confirmed the validity of present model for its full wavelength range. The $3^{\text {rd }} \& 4^{\text {th }}$ order elastic constant and its pressure derivatives for (EuTe) are given in Table 4. Which is probably the first reports in the 
absence of experimental data, but their reliability test is not possible. The reported result by use of SNTRSM for (EuTe) is comparatively nearer to the measure data on PDCs, which are showing in the Fig. 1(a), (b) \& (c). These results for TMC and its some features of PDC for (EUTe) are specially reporting here. The interactions of three body have affected both LO \& TO branches, more than acoustic branches (LA and TA). Other striking feature is excellent reproduction of optical and acoustic branch. The model parameter of TRSM \& TRIM is used to calculate the frequency along with uniformity and curve is plotted between wave vectors versus obtain (PD) from this model. These curves are measure up with use of inelastic neutron scattering technique. The specific heat data has been enumerating at variable temperature by Blackmann's ${ }^{17}$ and the Debye temperature curve is plotted with absolute temperature (T). Qualitatively the TRSM model is prominent than some of the model values. In addition, some other researchers ${ }^{18-22}$ of the same field of research have also tried to report their best to explain PDCs and other properties of europium chalcogenides but only with moderate success. To increase the merit of this work we have calculated 33 two phonon IR/Raman spectra and alteration of Debye temperatures shown in Fig. 2. The (CDS) peaks is compare with theoretical data, shown in Fig. 3. The interpretation of critical point study has been used by Burstein et al., ${ }^{23}$

\section{CONCLUSION}

Although, quantitively the agreement achieved from our present model TRSM is good. Furthermore, slight discrepancies still occurring between theory and experiment may be further improved by including the effect of free carrier screening (FCS), Van der Waals interactions (if data are available in future) and by including anharmonic vibrations in the present model (TRSM). A large group of researchers also have successfully reported theoretical results for some other alkali halides and semiconducting materials ${ }^{24-31}$ by use of the present model which shows the validity of this model.

\section{ACKNOWLEDGEMENT}

I am thankful to my respected principal Dr Sangeeta Gupta ,for her support and motivation.

\section{Conflict of interest}

Funding facility is not given by any agencies.

\section{REFERENCES}

1. Silberstein, R.P.; Tekippe, V.T.; Dresselhaus, M.S, Physics Rev., 1977, B16, 2728.

2. Zeyher,R.; Kress, W, Physics Rev., 1979, B20, 2850.

3. Smart, C.; Wilkinson, G. R.; Karo, A. M.; Hardy, J. R.; lattice Dynamics, edited by R.F.Wallis (Pergamon Press, Oxford), 1965.

4. Blackmann, M.; Z. Phys., 1933, 82, 421; Trans. Roy. Soc., 1955, A236, 102.

5. Wyckoff, R. W.G.; Crystal structure, (Wiley, New York)., 1963.

6. Guntherod, G.; Physics Condensed Matter., 1974, $18,37$.

7. Gupta, H. N.; Upadhyaya, R. S.; Physica Status Solidi., 1980, B102, 143.

8. Singh, R.K.; Gupta, H. N.; Proc. Royal Society London., 1976, 349, 289.

9. Mishra, V.; Sanyal, S. P.; Singh, R. K.; Phil. Mag., 1981, A55, 583.
10. Singh, R. K.; Gupta, H. N.; Sanyal, S. P.; IL Nuovo Cemento., 1980, 60, 89.

11. Lal, H.. H.; Verma, M .P.; Journal Phys. C, Solid State Physics., 1972, 5, 543.

12. Upadhyaya.; Kripa. S.; Yadav, M.; Upadhyaya, G. K.; Phys. Status Solidi., 2002, B229, 1129.

13. Singh, R. K.; Phys. Reports., 1982, 85, 259.

14. Kellerman, E.W.; Phil. Trans. Roy. Soc. (London)., 1940, A238, 513.

15. Woods, A. D. B.; Cochran, W.; Brockhouse, B. N.; Physical Review., 1960, 119, 980.

16. Verma, M. P.; Singh, R. K.; Physica Status Solidi., 1969, 33, 769.; 1969, 36, 335; 1970, 38, 851.

17. Blackmann, M.; Phys Z., Trans. Roy. Soc., 1955, A236, 102.

18. Sanyal, S. P.; Singh, R. K.; Physica B, 1985, 132, 201.

19. Mischenko, A. S.; Kikoin, K. A.; J. Phys. Codens. Matter., 1991, 3, 5937. 
20. Jha, P.K.; Sanyal, S.P.; Indian J.Pure and Applied. Physics., 1993, 31, 469.

21. Jha, K.; Sanyal, S.P.; Indian Journal of Pure and Applied Physics., 1994, 32, 824-829.

22. Jha, P. K.; Sanyal, S. P.; Pramana, Solid State Communication., 1998, 105, 455.

23. Burstein, E.; Jhonson, F.A.; Landon, R.; Phy. Rev., 1965, 139A, 1239.

24. Sakake, U. K.; Jha, P.K.; Sanyal, S. P.; Bull. Mat. Science., 2000, 23, 333.

25. Singh, S. P, Thesis Ph.D, Three body Interaction of lattice dynamics of Europium chalcogenides (V B S Purvanchal University, Jaunpur)., 2005.
26. Srivastava, U.C.; Upadhyaya, Kripa .S.; Rapid Communication (OAM-RC)., 2010, 4(9), 1336.

27. Srivastava. U. C.; Optoelectronics and Advanced Materials, Rapid Communications (OAM-RC)., 2013, I7(9-10), 698-701.

28. Srivastava, U.C.; International Journal of Modern Physics B., 2016, 30, 1750020-28.

29. Srivastava, U. C.; Journal of Science and Arts., 2017, 2(39 ), 309-320.

30. Singh, S. P.; Srivastava, U. C.; Upadhyaya, K. S.; International Journal of Scientific \& Technology Research (IJSTR)., 2021, 9(4), 472-478.

31. Srivastava, U. C.; Johnson Matthey Technol. Rev., 2021, 65(1), 87-93. 